Article

\title{
Consumption Structure in Urban and Rural Areas and Self-Rated Health of the Elderly: A Survey Based on Chinese General Social Survey
}

\author{
Zhaojing Liu * and Bin Li
}

check for updates

Citation: Liu, Z.; Li, B. Consumption Structure in Urban and Rural Areas and Self-Rated Health of the Elderly: A Survey Based on Chinese General Social Survey. Sustainability 2021, 13, 11530. https://doi.org/10.3390/ su132011530

Academic Editor: Giuseppe Battaglia

Received: 20 July 2021

Accepted: 12 October 2021

Published: 19 October 2021

Publisher's Note: MDPI stays neutral with regard to jurisdictional claims in published maps and institutional affiliations.

Copyright: (c) 2021 by the authors. Licensee MDPI, Basel, Switzerland. This article is an open access article distributed under the terms and conditions of the Creative Commons Attribution (CC BY) license (https:/ / creativecommons.org/licenses/by/ $4.0 /)$.
School of Public Administration, Central South University, Changsha 410083, China; libin@csu.edu.cn or leebin00@126.com

* Correspondence: society@csu.edu.cn

\begin{abstract}
Health inequality is an aspect of social inequality, and has now become an important problem in the current society. This article uses the data from the Chinese General Social Survey (2017) (CGSS2017) and uses the Multinomial Logistic Models method to analyze the elderly population (over 60 years old) across the country. The study found that the differences in the basic consumption of food and daily necessities among the elderly are relatively small; while consumer goods that reflect the differentiation of social classes such as clothing consumption and cultural consumption have a significant impact on the elderly. Travel consumption status also has a certain impact on the self-rated health choices of the elderly, but housing consumption has no effect on these choices. Thess results pave the way for investigating health from the perspective of socioeconomic status in academic circles. By using this consumption pattern analysis it is possible to analyze the health of the elderly population more effectively. In the future supply of consumer goods, it is possible to strengthen the consumption and supply of cultural tastes for the elderly, enhance the beauty and value of the lifestyle of the elderly, and increase the health of the elderly. At the same time, due to the significant impact of urban-rural differences in the health of the elderly, it is necessary to improve the living security level of the rural elderly, reduce the difference in public services between urban and rural elderly groups, and promote urban-rural integration.
\end{abstract}

Keywords: lifestyle health; stratified consumption structure; self-rated health; regional differences

\section{Introduction}

Social differences are common, and structural factors lead to social stratification and inequality. There is a consensus in academic circles that the main standard of social stratification is the type and possession level of resources, including economic resources, professional resources, political power resources, cultural resources, social relations resources, subjective reputation resources, civil rights resources and human resources. Due to the different resource types and possession levels, individuals belong to different social strata. Beck, a postmodern sociologist, put forward the theory of "individuation of social inequality" [1]. He believes that the traditional class structure that restricts people is gradually disappearing, the characteristics of an objective class structure and individual lifestyle are gradually separated, and individuals are increasingly likely to reinvent themselves [2]. Bourdieu, a French sociologist, believes that the differences in cultural forms, tastes and lifestyles are the most important factors [3]. He believes that habits gradually systematize to form a way of life, while creating a comprehensive quality of taste, behavior, and so on. Additionally, different groups have different consumption patterns. It is these different lifestyles and consumption patterns that make different groups present structural differences. In addition to the stratification of individuals, this has a great impact on individual survival and health, resulting in health inequality. 
Health inequality is one aspect of social inequality, and now it has become an important social problem. As the Greek doctor Hippocrates pointed out in "on air, water and space", environmental factors such as living habits or lifestyle, geographical topography and food quality affect people's health. Only by improving people's social environment can they live a better and healthier life. At present, scholars at home and abroad have reached a general consensus on the significant impact of socio-economic status on adult health. On the topic of this specific impact, some scholars also infer that lifestyle is the intermediary variable of socio-economic status affecting health [4]. Vietnamese scholars found that age has a greater impact on the health of the elderly, and with the increase in age, health inequality will become more and more prevalent; the inequality of consumption and community service levels will also directly affect health inequality [5].

The problem of health inequality has always been concerning. Especially when considering the guidance of Western countries, the international attention towards this problem is increasing. The Black Report, published by the United Kingdom, previously put forward the phenomenon of healthy social stratification. The social causality theory in the report points out that the health status of the groups with a higher socio-economic status was better than that of the groups with a low socio-economic status [6,7].

Compared with most scholars who discuss health inequality from the socio-economic status model and lifestyle model, some scholars also explore the impact of consumption patterns such as diet and drinking on health inequality. Consumers' interests in health is increasing. The field of consumption is a social field with a rich structure, in which food consumption, medical consumption, sports consumption, tourism consumption and cultural consumption in daily life constitute healthy promotion behavior [8]. Pursuing a healthy consumption lifestyle, including comprehensive consumption behaviors related to physical health, mental health and a healthy diet, is becoming more and more important for many people in Korea [9]. Golding and other Canadian scholars believe that, in the unprecedented period of COVID-19, the direct consumption of news media leads to depression and anxiety [10]. Bakkeli used Norwegian data to study consumption and housing ownership and proved that less consumption were significantly correlated with health, while housing property rights had no significant correlation with health [11]. Singapore scholars Herberholz and Elizabeth believe that the consumption of life experience makes people happier than the consumption of material goods. The reason why consumption does not create happiness is because the method and content of consumption are incorrect $[12,13]$. By studying the sample data of the elderly in the United States, American scholar Thomas Deleire found that there was a certain relationship between consumption structure and well-being, and there is no significant correlation between the consumption of durable goods, food, vehicles, housing and well-being, while there is a strong correlation between leisure consumption and well-being [14].

For elders, although the elderly do not have rigid needs in marriage, housing and education as young people might, they have prominent consumption needs in daily care, medical care, elderly care services, tourism and leisure. More and more elderly people build a certain social and cultural identity through their consumption lifestyles. Consumption has become an important factor to maintain identity, lifestyle and social distinction in later life. The elderly are increasingly pursuing a good quality of material life, high quality of spiritual life and deep participation in social life. Basic living expenditure and health consumption are the main consumption factors of the elderly population. The demand for culture, entertainment, health and pensions is increasing. There is a clear regional, urban-rural and age gap in basic living expenditure [15]. However, some scholars hold the opposite opinion. They believe that food consumption and medical consumption account for most of the consumption structure of the elderly, but the expenditure on culture, entertainment and travel decreased significantly [16]. Additionally, due to the difference between urban and rural areas caused by registered residence differences in China, these differences resulted in a larger social gap between urban and rural areas due to differences in education, income and economic development levels. In terms of the utilization and 
service of personal health information and the formulation of health decision-making, urban areas are nearly double that of rural areas with a significant difference [17]. There is also a large gap in the accessibility of health and medical services. The life expectancy of the urban population, as well as the number of medical facilities and medical staff are more abundant than those in rural areas [18,19]. However, the academic community has not yet formed the same cognition about the urban-rural differences of the elderly. Regarding the physiological aspects, such as daily activity ability, or the psychological aspects such as cognition and self-rated health, scholars have different views. Some believe that the urban elderly are better than the rural elderly, some think that the rural elderly are better than the urban elderly, but some think that there is no significant difference between the two [20-24].

In China, with the improvement in income level, after people meet the basic living consumption, the consumption level, consumption structure and the resulting lifestyle also undergo important changes, that is, consumption stratification. Yet, consumption stratification is still closely related to occupation and economic level [25]. From Weber's description of a healthy lifestyle, we can see that he advocates for pursuing a healthy lifestyle, that is, individuals try to produce good health according to their own motivations, effort and ability levels, and he regards the goal of these activities as a kind of consumption [15]. Bourdieu believes that consumption, as a kind of expressive practice, is a symbol of people's social status. People's consumption preferences can better reflect their social class than the traditional criteria of income, occupation and rights [25]. Based on the analysis of the survey data of France in 1972, he believes that in the annual consumption of teachers, professional and technical personnel, industrial and commercial employers, the amount spent on diet, external performance and culture is different. Relatively speaking, industrial and commercial owners pay more attention to diet consumption, teachers pay more attention to cultural consumption, and professional and technical personnel pay more attention to external performance. Wagstaff and colleagues conducted a study on health inequality, based on the data of Vietnam from 1993 to 1998, and found that the health inequality represented by height difference could be largely explained by the inequality of consumption and community service [26].

This paper mainly discusses the lifestyle, consumption structure, differences between urban and rural areas, and the relationship between these areas and health. In the academic sense, this topic can verify the applicability of "health inequality caused by social inequality in the field of health", "healthy socio-economic status determinism" and "healthy lifestyle theory" in China's urban and rural elderly groups, and answer theoretical questions such as whether consumption structure can affect urban residents' health. In a practical sense, this topic can help us understand the correlation mechanism between the objective lifestyle and subjective health of urban and rural elderly groups in China, and understand how individual health status is shaped by the group or society. More importantly, although the self-rated health used in this paper is a subjective stratified indicator, its credibility as a mortality prediction indicator is increasing [27]. This indicator can provide a greater reference for the future development of a series of health planning and policies.

\section{Materials and Methods}

\subsection{Material}

The data of this study are from the Chinese General Social Survey (2017) (cgss2017), which is jointly implemented by the National Survey Research Center of Renmin University of China and academic institutions from all over the country. Stratified design and multi-stage PPS sampling method are used to analyze the overall urban and rural populations (over 18 years old, excluding Hong Kong, Macao and Taiwan) of 31 provinces and autonomous regions in China. A total of 12582 samples were obtained and the questionnaire was derived from the data obtained from face-to-face interviews. However, due to the health status of the elderly investigated in this paper, according to the international standard, this paper selects the samples over 60 years old to enter the analysis, and the 
actual number of effective samples is 4372 . In the analysis, some missing variables were treated as missing values.

\subsection{Methods}

This paper takes the "self-rated health of elderly residents" as the dependent variable, and takes the 15th question of the questionnaire "what do you think your current health status is" as the explanatory variable of this study; The options for this question are classified into one category, namely "unhealthy, general and healthy", and assigned " $1-3$ " to represent the order from low to high.

Consumption is a kind of daily practice and the embodiment of habits and values dominated by a way of life $[28,29]$. We chose five indicators representing people's general consumption level in household consumption expenditure, including "clothing, food, housing, transportation and use", plus "cultural" consumption.

In this paper, the variables, including demographic information, were included in the model as control variables, including age, gender, marriage and household registration. In addition, as mentioned above, the impact of physical exercise and socioeconomic status variables on health was confirmed by the academic community, so they were also included in the control variables. As Marx said, the basis of consumption is income, and the ability of consumption is the condition and basis of consumption [30], the logarithm of the individual annual income is selected as the income variable and is included in the model for control.

This paper uses multinomial logistic models for analysis. Firstly, demographic variables such as age, gender, marital status, annual income and physical exercise are included in the basic model, and household registration is taken as an indicator of urban-rural differentiation, which is regressed by self-rated health. Then, the consumption structure of "clothing, food, housing, transportation, use and culture" is included in the model, and the self-rated health is regressed to investigate the impact of consumption structure stratification on self-rated health. Finally, through the comparative analysis of the three categories of self-rated health "unhealthy, general and healthy", the influence of consumer behavior on different categories of self-rated health is investigated.

\section{Results}

This study made descriptive statistical analysis of all variables to see the basic situation of variables. Additionally, it used demographic variables such as gender, age and marital status as control variables to verify the applicability of the demographic factors to the health of the elderly. At the same time, for the social and economic status factors represented by annual income and the lifestyle factors represented by physical exercise and consumption, structure factors were used to verify whether they were applicable to the elderly group. The urban-rural differences based on household registration were used to investigate the health status of the elderly between urban and rural areas.

\subsection{Descriptive Analysis}

The study summarizes the variables involved through descriptive analysis. In this study, "self-rated health" ranges from 1 to 5 , and the number from small to large represents the degree of health, from "very unhealthy" to "healthy". As shown in Table 1, the minimum value is 1 , the maximum value is 3 , and the mean value is 1.9 , which means that the average selection of the whole data is relatively unhealthy. Therefore, in the regression analysis, the five categories of 1-5 are redivided into three categories. The six variables of "food consumption, clothing consumption, residential consumption, daily necessities consumption, travel consumption and cultural consumption" are continuous variables, which are logarithmicized in this paper. The values in Table 1 are the logarithm values. It can be seen that the consumption of diet is the highest relative value, followed by the consumption of daily necessities, and the lowest value is the residential consumption, because these elderly people do not encounter housing problems. In terms of age, it can be seen from Table 1 that 60 is the research object delimited in this paper. The youngest 
person was 60 and the oldest was 103, with an average age of 69.4 years. The sex ratio was effectively 1:1. In terms of registered residence, the ratio of urban-rural residents was also effectively 1:1. However, in terms of marital status, the proportion of cohabitation with an an older wife is highest, the average income is 130.92 million yuan, and the frequency of physical exercise was, on average, 2.4 times per week. Table 1 shows the descriptive statistics of all variables. In this paper, the correlation coefficients between all independent variables were tested, and no collinearity problem was found.

Table 1. Descriptive statistics of all variables.

\begin{tabular}{cccccc}
\hline Variable & $\mathbf{N}$ & Mean & SD & Minimum & Maximum \\
\hline $\begin{array}{c}\text { Dependent variable } \\
\text { Self-rated health }\end{array}$ & 4367 & 1.993 & 0.834 & 1 & 3 \\
$\begin{array}{c}\text { Explanatory variable } \\
\text { Food consumption }\end{array}$ & 1263 & 8.738 & 1.670 & 0 & 16.12 \\
$\quad$ Clothing consumption & 1268 & 5.646 & 3.246 & 0 & 16.12 \\
$\quad$ Residential consumption & 1313 & 1.845 & 3.535 & 0 & 16.12 \\
Consumption of daily necessities & 1255 & 6.279 & 2.521 & 0 & 16.12 \\
$\quad$ Travel consumption & 1295 & 3.661 & 3.693 & 0 & 16.12 \\
$\quad$ Cultural consumption & 1317 & 2.023 & 3.663 & 0 & 16.12 \\
Control variable & & & & & \\
$\quad$ Age & 4372 & 69.38 & 7.393 & 60 & 103 \\
$\quad$ Gender (male = 1) & 4372 & 0.485 & 0.500 & 0 & 1 \\
$\quad$ Marriage (cohabitation =1) & 4372 & 0.724 & 0.447 & 0 & 1 \\
Registered residence (city =1) & 4352 & 0.483 & 0.500 & 0 & 1 \\
$\quad$ Annual income & 4189 & 8.117 & 3.544 & 0 & 16.12 \\
Physical exercise (Times) & 4349 & 2.405 & 4.698 & 0 & 84 \\
\hline$\quad$ & & & & & \\
\hline
\end{tabular}

\subsection{Differences of Healthy Lifestyle and Health Level between Urban and Rural Elderly}

Table 2 shows the self-evaluation model of gender, age, marital status, annual income, physical exercise, household registration and other variables for the health of the elderly. We can see that, in the two models, the influence of demographic variables such as gender and age on self-rated health is significant, and there is no significant difference in marital status. As an important indicator of social and economic status, annual income shows a significant difference, and physical exercise, as an indicator of lifestyle, also shows a significant difference. Specifically, compared with the elderly who chose "unhealthy", after controlling for other factors, the elderly who chose "general" and "healthy" in their self-rated health were 1.18 times and 1.46 times as healthy as the female residents, respectively. With the age increasing by one year, the probability of choosing "general" and "healthy" decreased by $1.28 \%$ and $1.44 \%$.

When the social and economic status factors represented by annual income were investigated and compared with the elderly who chose "unhealthy", after controlling for other factors, the probability of self-rated health being "general" and "healthy" increased by $6.8 \%$ and $9.0 \%$ for each natural index of income increase. Compared with the elderly who choose "unhealthy" lifestyle factors represented by physical exercise, after controlling for other factors, the probability of choosing "general" and "healthy" in self-rated health increases by $6.8 \%$ and $9.0 \%$ for each natural index of income increase. Essentially, the positive influence of demographic factors such as gender on the self-rated health of the elderly group has been proven, and the negative influence of age on the self-rated health of the elderly group has also been proven, which shows that the older the elderly group is, the unhealthier it is, while the influence of marital status is not significant. The social and economic status factors represented by income and lifestyle factors represented by physical exercise also have a positive impact on the self-rated health of the elderly. In the investigation of urban-rural differences on health, this paper divides Hukou into urban and rural areas. In the model fitting, the urban elderly chose "general" and "healthy" in the self-rated health, which was 1.87 times and 1.62 times greater than the rural elderly, 
showing a significant difference at the level of 0.001 . This fully proves the differences between urban and rural areas in the health stratification of the elderly.

Table 2. Multinomial Logistic Model of self-rated health, socioeconomic status and lifestyle of the elderly.

\begin{tabular}{ccc}
\hline Variable & General/Unhealthy & Healthy/Unhealthy \\
\hline Gender $($ male $=1)$ & $0.162^{*}$ & $0.377^{* * *}$ \\
Age & $(0.0812)$ & $(0.0793)$ \\
& $-0.0129^{*}$ & $-0.0145^{* *}$ \\
Marriage (cohabitation $=1)$ & $(0.00563)$ & $(0.00556)$ \\
& -0.121 & 0.0403 \\
Annual income (logarithm) & $(0.0929)$ & $(0.0927)$ \\
Physical exercise (Times) & $0.0661^{* * *}$ & $0.0863^{* * *}$ \\
& $(0.0124)$ & $(0.0125)$ \\
Registered residence (city $=1)$ & $0.0397^{* * *}$ & $0.0695^{* * *}$ \\
& $(0.0119)$ & $(0.0114)$ \\
_cons & $0.628^{* * *}$ & $0.484^{* * *}$ \\
& $(0.0908)$ & $(0.0890)$ \\
& -0.105 & -0.279 \\
& $(0.426)$ & $(0.421)$ \\
\hline
\end{tabular}

Standard errors in parentheses. ${ }^{*} p<0.05,{ }^{* *} p<0.01,{ }^{* * *} p<0.001$.

\subsection{Consumption Structure of the Elderly in Urban and Rural Areas of China and Their Self-Rated "General" Health}

In order to analyze the influence of the consumption structure of the elderly on their self-rated "general" health, the study divides self-rated health into three categories: "unhealthy, general and healthy", and uses multinomial logistic models to estimate the impact of basic control variables and the consumption structure on the self-rated health of the urban and rural elderly in China. Table 3 shows the model comparison results between the self-rated general and self-rated unhealthy residents.

Clothing, food, housing, and transportation use are the basic factors of material life, while culture is an important part of spiritual life. For the elderly, material life and spiritual life are important aspects of life. Therefore, this study from clothing, food, housing, transportation, use, culture and the other six basic consumption structures, on the basis of the basic model, constructed a six consumption structure model, and then investigated the influence of the stratification of the consumption structure on the self-rated health of the elderly group. From the estimation results, when the consumption structure factor was added, the significant influence of the gender factor on the health of the elderly in the basic model disappeared. Similarly, the significance of marital status, physical exercise and the other two factors in the basic model also disappeared. This showed that, compared with the elderly who chose "unhealthy", self-rated health, gender, marital status, physical exercise and other factors in the basic model were significantly different. There was no significant difference between physical exercise and self-rated health choice.

In the new consumption structure model, clothing consumption model, and travel consumption model, the daily necessities consumption model and cultural consumption model all show significant differences, while the consumption model of diet and residence do not show significant differences. This demonstrates that, compared with the people who have a self-rated choice of "unhealthy", people who choose the self-rated choice of "general" pay more attention to clothing consumption, travel consumption, daily necessities consumption and cultural consumption; clothing, travel, daily necessities, cultural consumption stratification has a positive impact on self-rated health. In terms of the differences between urban and rural areas, the six consumption models show significant differences, which indicate that there are great differences in the stratification of the consumption structure between urban and rural areas. The differences between urban and rural areas have a positive impact on the self-rated health of the elderly. 
Table 3. Multi-Nomial Logistic Models of consumption structure stratification and the self-rated health of the elderly (Comparison between self-rated general and self-rated unhealthy).

\begin{tabular}{|c|c|c|c|c|c|c|c|}
\hline Variable & $\begin{array}{l}\text { Basic } \\
\text { Model }\end{array}$ & $\begin{array}{l}\text { Clothing } \\
\text { Model }\end{array}$ & $\begin{array}{c}\text { Diet } \\
\text { Model }\end{array}$ & $\begin{array}{l}\text { Residential } \\
\text { Model }\end{array}$ & $\begin{array}{l}\text { Travel } \\
\text { Model }\end{array}$ & $\begin{array}{l}\text { Daily Use } \\
\text { Model }\end{array}$ & $\begin{array}{c}\text { Cultural } \\
\text { Model }\end{array}$ \\
\hline \multirow{2}{*}{ Gender $($ male $=1)$} & $0.162 *$ & 0.243 & 0.205 & 0.230 & 0.162 & 0.179 & 0.208 \\
\hline & $(0.0812)$ & $(0.151)$ & $(0.151)$ & $(0.147)$ & $(0.150)$ & $(0.152)$ & $(0.147)$ \\
\hline \multirow{2}{*}{ Age } & -0.0129 * & -0.0154 & -0.0147 & -0.0205 * & -0.0120 & -0.0195 & -0.0180 \\
\hline & $(0.00563)$ & $(0.0107)$ & $(0.0106)$ & $(0.0103)$ & $(0.0106)$ & $(0.0107)$ & $(0.0103)$ \\
\hline Marriage & -0.121 & 0.0486 & 0.0784 & 0.153 & 0.0966 & 0.0886 & 0.133 \\
\hline$($ cohabitation $=1)$ & $(0.0929)$ & $(0.170)$ & $(0.171)$ & $(0.167)$ & $(0.169)$ & $(0.170)$ & $(0.167)$ \\
\hline registered residence & $0.628^{* * *}$ & 0.445 * & 0.424 * & $0.515^{* *}$ & $0.498 * *$ & $0.503^{* *}$ & $0.421^{*}$ \\
\hline$($ city $=1)$ & $(0.0908)$ & $(0.174)$ & $(0.181)$ & $(0.169)$ & $(0.171)$ & $(0.176)$ & $(0.174)$ \\
\hline Annual income & $0.0661^{* * *}$ & $0.0876^{* * *}$ & $0.0776^{* *}$ & $0.0860^{* * *}$ & $0.0890^{* * *}$ & $0.0808^{* * *}$ & $0.0838^{* * *}$ \\
\hline (logarithm) & $(0.0124)$ & $(0.0241)$ & $(0.0242)$ & $(0.0237)$ & $(0.0237)$ & $(0.0241)$ & $(0.0233)$ \\
\hline Physical exercise & $0.0397^{* * *}$ & 0.0229 & 0.0465 & 0.0211 & 0.0415 & 0.0304 & 0.00550 \\
\hline (Times) & $(0.0119)$ & $(0.0245)$ & $(0.0257)$ & $(0.0234)$ & $(0.0253)$ & $(0.0243)$ & $(0.0228)$ \\
\hline Consumption & & $0.0929^{* * *}$ & & & & & \\
\hline structure (clothing) & & $(0.0233)$ & & & & & \\
\hline Consumption & & & 0.0932 & & & & \\
\hline structure (diet) & & & $(0.0497)$ & & & & \\
\hline Consumption & & & & 0.00853 & & & \\
\hline structure (residence) & & & & $(0.0216)$ & & & \\
\hline Consumption & & & & & 0.0527 * & & \\
\hline structure (travel) & & & & & $(0.0206)$ & & \\
\hline Consumption & & & & & & 0.0642 * & \\
\hline structure (daily use) & & & & & & $(0.0299)$ & \\
\hline Consumption & & & & & & & $0.0817^{* * *}$ \\
\hline structure (Culture) & & & & & & & $(0.0244)$ \\
\hline cons & -0.105 & -0.513 & -0.816 & 0.219 & -0.445 & -0.114 & 0.103 \\
\hline _cons & $(0.426)$ & $(0.816)$ & $(0.910)$ & $(0.773)$ & $(0.805)$ & $(0.814)$ & $(0.773)$ \\
\hline $\mathrm{N}$ & 4146 & 1222 & 1214 & 1262 & 1245 & 1207 & 1263 \\
\hline pseudo R2 & 0.037 & 0.061 & 0.056 & 0.046 & 0.055 & 0.054 & 0.054 \\
\hline
\end{tabular}

Standard errors in parentheses. ${ }^{*} p<0.05,{ }^{* *} p<0.01,{ }^{* * *} p<0.001$.

\subsection{Consumption Structure of the Elderly in Urban and Rural China and Their Self-Rated "Health"}

In order to analyze the influence of the consumption structure of the elderly on the self-rated health of the elderly, the multinomial logistic regression model was used to estimate the basic control variables and the influence of the consumption structure on the self-rated health of the elderly in urban and rural areas of China. Table 4 shows the model comparison results between the self-rated healthy and self-rated unhealthy.

Similarly, starting from the six basic consumption structure stratifications of clothing, food, housing, transportation, daily use and culture, this paper constructs six consumption structure stratification models on the basis of the original determined basic model, and tests the influence of six consumption structure stratifications on the self-rated health (comparison between healthy and unhealthy) in turn. Firstly, in the basic model, there are significant differences in gender, age, urban-rural differences, income and exercise. From the estimated results, after adding the consumption structure factor, the significant influence of the age factor on the health of the elderly in the basic model disappears. In the clothing consumption model, there are significant differences in clothing consumption, which show that, compared with the self-rated healthy elderly who choose "unhealthy", the self-rated healthy elderly who choose "healthy" have a higher clothing consumption. Similarly, after controlling income, exercise, urban-rural differences, marital status, age, gender and other factors, clothing consumption, food consumption, travel consumption, daily necessities consumption and cultural consumption all show significant differences. In other words, compared with the elderly who choose "unhealthy", the elderly who choose 
"healthy" have a higher probability of higher clothing consumption, diet consumption, travel consumption, daily necessities consumption and cultural consumption, etc.

Table 4. Multinomial Logistic Models of consumption structure stratification and self-rated health of the elderly (Comparison between self-rated healthy and self-rated unhealthy).

\begin{tabular}{|c|c|c|c|c|c|c|c|}
\hline Variable & $\begin{array}{c}\text { Basic } \\
\text { Model }\end{array}$ & $\begin{array}{l}\text { Clothing } \\
\text { Model }\end{array}$ & $\begin{array}{c}\text { Diet } \\
\text { Model }\end{array}$ & $\begin{array}{c}\text { Residential } \\
\text { Model }\end{array}$ & $\begin{array}{l}\text { Travel } \\
\text { Model }\end{array}$ & $\begin{array}{l}\text { Daily Use } \\
\text { Model }\end{array}$ & $\begin{array}{c}\text { Cultural } \\
\text { Model }\end{array}$ \\
\hline Gender $($ male $=1)$ & $\begin{array}{l}0.377^{* * *} \\
(0.0793)\end{array}$ & $\begin{array}{l}0.312 * \\
(0.153)\end{array}$ & $\begin{array}{c}0.225 \\
(0.153)\end{array}$ & $\begin{array}{c}0.263 \\
(0.148)\end{array}$ & $\begin{array}{c}0.252 \\
(0.151)\end{array}$ & $\begin{array}{c}0.292 \\
(0.154)\end{array}$ & $\begin{array}{c}0.283 \\
(0.150)\end{array}$ \\
\hline Age & $\begin{array}{l}-0.0145^{* *} \\
(0.00556)\end{array}$ & $\begin{array}{c}-0.00627 \\
(0.0109)\end{array}$ & $\begin{array}{c}-0.00953 \\
(0.0108)\end{array}$ & $\begin{array}{l}-0.0111 \\
(0.0103)\end{array}$ & $\begin{array}{c}-0.00325 \\
(0.0108)\end{array}$ & $\begin{array}{l}-0.0154 \\
(0.0108)\end{array}$ & $\begin{array}{c}-0.00768 \\
(0.0105)\end{array}$ \\
\hline Marriage & $\begin{array}{l}0.0403 \\
(0.0927)\end{array}$ & 0.0358 & 0.0262 & 0.128 & 0.0620 & 0.0487 & 0.0705 \\
\hline registered residence & $0.484^{* * *}$ & 0.199 & 0.0533 & $0.342 *$ & 0.309 & 0.209 & 0.133 \\
\hline$($ city $=1)$ & $(0.0890)$ & $(0.179)$ & $(0.188)$ & $(0.171)$ & $(0.175)$ & $(0.180)$ & $(0.179)$ \\
\hline $\begin{array}{l}\text { Annual income } \\
\text { (logarithm) }\end{array}$ & $\begin{array}{c}0.0863 * * * \\
(0.0125)\end{array}$ & $\begin{array}{l}0.126^{* * *} \\
(0.0262)\end{array}$ & $\begin{array}{l}0.124^{* * *} \\
(0.0269)\end{array}$ & $\begin{array}{l}0.115^{* * *} \\
(0.0251)\end{array}$ & $\begin{array}{l}0.117^{* * *} \\
(0.0254)\end{array}$ & $\begin{array}{l}0.121^{* * *} \\
(0.0263)\end{array}$ & $\begin{array}{l}0.116^{* * *} \\
(0.0251)\end{array}$ \\
\hline Physical exercise & $0.0695^{* * *}$ & $0.0848^{* * *}$ & $0.121^{* * *}$ & $0.0837^{* * *}$ & $0.116^{* * *}$ & $0.0946^{* * *}$ & $0.0681^{* *}$ \\
\hline (Times) & $(0.0114)$ & $(0.0235)$ & $(0.0249)$ & $(0.0222)$ & $(0.0243)$ & $(0.0234)$ & $(0.0212)$ \\
\hline $\begin{array}{c}\text { Consumption } \\
\text { structure (clothing) }\end{array}$ & & $\begin{array}{l}0.137^{* * *} \\
(0.0244)\end{array}$ & & & & & \\
\hline $\begin{array}{l}\text { Consumption } \\
\text { structure (diet) }\end{array}$ & & & $\begin{array}{l}0.214^{* * *} \\
(0.0572)\end{array}$ & & & & \\
\hline $\begin{array}{l}\text { Consumption } \\
\text { structure (residence) }\end{array}$ & & & & $\begin{array}{c}0.0385 \\
(0.0209)\end{array}$ & & & \\
\hline $\begin{array}{l}\text { Consumption } \\
\text { structure (travel) }\end{array}$ & & & & & $\begin{array}{l}0.0664 * * \\
(0.0208)\end{array}$ & & \\
\hline $\begin{array}{l}\text { Consumption } \\
\text { structure (daily use) }\end{array}$ & & & & & & $\begin{array}{l}0.118^{* * *} \\
(0.0317)\end{array}$ & \\
\hline $\begin{array}{c}\text { Consumption } \\
\text { structure (Culture) }\end{array}$ & & & & & & & $\begin{array}{l}0.116^{* * *} \\
(0.0242)\end{array}$ \\
\hline _cons & $\begin{array}{l}-0.279 \\
(0.421)\end{array}$ & $\begin{array}{l}-1.769^{*} \\
(0.841)\end{array}$ & $\begin{array}{l}-2.612^{* *} \\
(0.960)\end{array}$ & $\begin{array}{l}-0.778 \\
(0.782)\end{array}$ & $\begin{array}{l}-1.435 \\
(0.822)\end{array}$ & $\begin{array}{l}-1.100 \\
(0.836)\end{array}$ & $\begin{array}{l}-0.971 \\
(0.793)\end{array}$ \\
\hline $\mathrm{N}$ & 4146 & 1222 & 1214 & 1262 & 1245 & 1207 & 1263 \\
\hline pseudo R2 & 0.037 & 0.061 & 0.056 & 0.046 & 0.055 & 0.054 & 0.054 \\
\hline
\end{tabular}

Standard errors in parentheses. ${ }^{*} p<0.05,{ }^{* *} p<0.01,{ }^{* * *} p<0.001$.

\section{Discussion}

The study found that the consumption structure has an impact on the self-rated health of the elderly to a certain extent. Specifically, clothing consumption, cultural consumption and other consumer goods reflecting social stratum differentiation have a significant impact on the self-rated health choices of the elderly [10]. In this study, clothing consumption and cultural consumption have a positive and significant impact on the elderly group which choose "general health". It may be that the consumption of clothing and culture can represent the consumption taste and consumption habits of the elderly group. These consumption factors play a more important role in the health of the elderly group, which is also an important embodiment of class differentiation. Just as Bourdieu argued, different social classes face different life consumptions, and people in distress are bound to be troubled by daily life consumption [3]. In this study, the elderly have little difference in the basic consumption such as diet and daily necessities. When investigating the impact of the basic consumption such as diet and daily necessities on the health of the elderly, by comparing the groups who choose "general" and "unhealthy", it is found that there is no significant difference between them in diet consumption, and there is a weak significant difference between them in daily necessities consumption. When comparing the "healthy" and "general" elderly groups selected by self-rated health, there are strong significant differences in diet consumption and commodity consumption. In some cases, this shows 
that basic consumption plays a certain role in the self-rated health choices of the elderly. This aspect confirms the previous debate among scholars on the inconsistent impact of basic consumption, such as the diet on health $[15,16]$. In the aspect of the Chinese diet, there are always differences in diet consumption, such as "eat enough, eat well, eat grass, and take medicine". People's choice of diet consumption from the satisfaction of food and clothing to enjoyment represents the differences and choices associated with different consumption levels [31].

According to the French Institute of Social Sciences, the smaller the per capita area of a house, the smaller the private space of an individual, which leads to the tension and pressure of an interpersonal relationship. The influence of this social and cultural process eventually affects the decline or maintenance of people's health status [32]. In this study, housing consumption has no impact on the self-rated health choice of the elderly group, while the travel consumption status shows significant differences in the "general vs. unhealthy" consumption model and the "healthy vs. general" consumption model, indicating that the travel status has a certain impact on the health of the elderly group. This reflects the same results as Bakkeli and colleagues that housing has no significant impact on individual health [11]. This may be related to the implementation of the housing commercialization system reform in China in the 1990s. The elderly groups studied in this paper were born around 1957, thus the impact of the housing commercialization policy for them is relatively small, effectively causing no problems with housing consumption. The elders with a high travel consumption are more likely to choose health, which proves that the elderly group has higher travel and tourism demand $[14,15]$.

Sociologists, Glazer and Moynihan, put forward the term "structural difference" to reflect the differences of social environment [33]. The differences between urban and rural areas in China can also be regarded as the overall structural livelihood problems in China [34]. In this study, there are great differences in the self-rated health choices between urban elderly groups and rural elderly groups. In the basic model and all consumption models of "general vs. unhealthy", the rural elderly groups have a greater probability of choosing self-rated "unhealthy". The reason for this is that, compared with the rural elderly groups, the urban elderly groups may have better public services. For example, they are living relatively close to the hospital, the urban environment and community environment are relatively good, and they can easily enjoy the convenient and beautiful environment of life. This is also different from the urban-rural differences that scholars have been debating about [20-24].

This paper uses the data from China's urban and rural elderly groups in the national sampling survey to investigate, from the perspective of health stratification, the stratification effect of consumption structure and stratification, urban and rural regional differentiation and other factors on health. We believe that, under the same economic income, the structural difference and stratification of consumption will still have a hierarchical impact on the health of the elderly.

\section{Conclusions}

Our research shows that there are great differences between urban and rural areas in the self-rated health of elderly groups. Urban elderly groups may have better public services. For example, they are relatively close to hospitals, and the urban and community environment is supportive, so they can easily enjoy a convenient and high quality of life. The consumption structure, as an embodiment of a way of life, has structural differences in its relationship with the health of the elderly. The elderly's basic consumption, such as diet and daily necessities, has little impact on their health. The impact of the housing commercialization policy on them is relatively small, and thus there is effectively no housing consumption problem. Clothing consumption, cultural consumption and other consumer goods reflecting social stratum differentiation have a significant impact on the self-rated health choices of the elderly. The clothing consumption and cultural consumption have a positive and significant impact on the "general health" of the health choices of the 
elderly groups. Both clothing and cultural consumption represent the consumption tastes and habits of the elderly group. These represent the consumption of stratum differentiation, which plays in an important role in the health of the elderly group.

The preference of consumption structure is the embodiment of a lifestyle. This study advances beyond the original simple generalization of lifestyle from the perspective of diet and exercise and reveals the impact of lifestyle on the health of the elderly from the perspective of a more comprehensive consumption structure. For the elderly group, the preference of consumption structure represents the characteristics of individual lifestyle, and it is also an important embodiment of the culture, knowledge and habits of the elderly group. Paying attention to the differentiation of the consumption structure is to understand the differences of lifestyles. Through the analysis of the consumption structure representing lifestyles, we can comprehensively judge the health stratification status of the elderly group and lay a foundation for the prediction and analysis of the health status of the elderly group in the future.

Because the influencing factors of health are very complex, our research investigates the elderly group from the perspective of the overall consumption of consumption structures, advancing beyond the narrow framework of the original lifestyle of physical exercise and diet. In the future research, we need to refine the index factors of the consumption structures, restore the realistic scene of specific life as much as possible, and explore the impact of the consumption structure on the health of the elderly group from the method of qualitative research. At the same time, it is also necessary to divide the health of the elderly into mental health and physical health and to investigate the impact of consumption structures on mental and physical health, respectively. These all require new system solutions to support future research.

Author Contributions: Conceptualization, Z.L.; writing—original draft preparation, Z.L.; writingreview and editing, Z.L.; supervision, B.L. All authors have read and agreed to the published version of the manuscript.

Funding: This research received no external funding.

Institutional Review Board Statement: Not applicable.

Informed Consent Statement: Not applicable.

Data Availability Statement: The data presented in this study are available on the website of Chinese General Social Survey (http:/ / cnsda.ruc.edu.cn/index.php?r=site/article\&id=180, accessed on 15 October 2021).

Conflicts of Interest: The authors declare no conflict of interest.

\section{References}

1. Beck, U. The Individualization of Social Inequality: The Disappearance of Life Forms and Traditions. In Risk Society; He, B., Translator; Yilin Publishing House: Nanjing, China, 2004; Volume 7, pp. 105-110.

2. Chao, H. Household Income, Wealth and Status Identification Among Chinese Adults. Sociol. Stud. 2020, 35, 195-218.

3. Bourdieu, P. Distinction: A Social Critique of the Judgement of Taste; Harvard University Press: Cambridge, MA, USA, 1984.

4. Huang, J.-P.; Yin, Q.-J. The Effects of Socioeconomic Status on Health: Based on Lifestyle Mediator. Popul. Econ. 2013, 198, 26-34.

5. Xiao, H. Whether the Income-related Health Inequality has Increased. Stat. Res. 2012, 29, 51-59.

6. Feinstein, J.S. The Relationship between Socioeconomic Status and Health: A Review of the Literature. Milbank Q. 1993, 71, 279-322. [CrossRef] [PubMed]

7. Liu, Z.-X. Health responsibility and health justice. Gansu Soc. Sci. 2006, 4, 110-113.

8. Wang, C.; Li, L. Type of Consumer Health-Enhancing Behaviors and Its Formation Mechanism. Adv. Psychol. Sci. 2015, 23, 679. [CrossRef]

9. Kim, M.-S.; Seo, J.-H.; Jeon, H.-R. A Study on the Health-Seeking Consumption Lifestyle of Married Women. Korean J. Hum. Ecol. 2012, 21, 489-503. [CrossRef]

10. Golding, M.A.; Salisbury, M.R.; Reynolds, K.; Roos, L.E.; Protudjer, J.L.P. COVID-19-related media consumption and parental mental health. Can. J. Behav. Sci. Rev. Can. Sci. Comport. 2021, 53, 371-376. [CrossRef]

11. Bakkeli, N.Z. Health and economic scarcity: Measuring scarcity through consumption, income and home ownership indicators in Norway. SSM Popul. Health 2020, 11, 100582. [CrossRef] 
12. Herberholz, C.; Prapaipanich, N. Conspicuous consumption of online social networking devices and subjective well-being of bangkokians. Singap. Econ. Rev. 2019, 64, 1371-1395. [CrossRef]

13. Dunn, E.W.; Gilbert, D.T.; Wilson, T.D. If money doesn't make you happy, then you probably aren't spending it right. J. Consum. Psychol. 2011, 21, 115-125. [CrossRef]

14. DeLeire, T.; Kalil, A. Does consumption buy happiness? Evidence from the United States. Int. Rev. Econ. 2010, 57, 163-176. [CrossRef]

15. Zeng, H.; Fan, X. Further stimulating the silver hair consumer market. Macroecon. Manag. 2019, 431, 33-38.

16. Luo, Y. Consumption Structure and Marketing Strategy of the Elderly. Available online: https://epaper.gmw.cn/gmrb/html/20 13-04/16/nw.D110000gmrb_20130416_2-07.htm?div=-1 (accessed on 16 April 2013).

17. Yao, H.-W.; Shi, Q.-L.; Ying, H. The Current Status of Health Literacy in China. Popul. Res. 2016, 40, 88-97.

18. Zhao, Z. Income Inequality, Unequal Health Care Access, and Mortality in China. Popul. Dev. Rev. 2006, 32, 461-483. [CrossRef]

19. Li, J.-X.; Li, C.-H. Health Difference of the Elderly between the Rural and Urban Districts. Popul. J. 2014, $36,37-47$.

20. Fang, X.H.; Meng, S.; Liu, X.H.; Wu, X.G.; Liu, H.J.; Diao, L.J.; Tang, Z. Study on the relationship between self-rated health situation and health status in the elderly-an 8-year follow-up study from Multi-Dimentional Longitudinal Study of Aging in Beijing. Chin. J. Epidemiol. 2003, 3, 19-23.

21. Zhou, G. Self-rated Health of Chinese Elderly: Differential and Development. South China Popul. 2008, $23,51-58$.

22. Yi, Z.; Ke, S. Main dimensions of health status among the Chinese elderly. Zhonghua Yu Fang YiXue ZaZhi Chin. J. Prev. Med. 2010, $44,108-114$.

23. Meng, Q.-Q.; Zhang, T.-H. Determinants of self-rated health in old people. Beijing Da Xue Xue Bao J. Peking Univ. Health Sci. 2010, $42,258-263$.

24. Li, T.; Wu, H.; Yang, M.; Shen, J.; Dong, B. A systematic review of the influence of lifestyle on self-rated health of the elderly in China. Chin. J. Gerontol. 2011, 31, 4423-4426.

25. Tian, F. Consumption, lifestyle and social stratification. Heilongjiang Soc. Sci. 2011, 1, 88-97.

26. Wagstaff, A.; van Doorslaer, E.; Watanabe, N. On decomposing the causes of health sector inequalities with an application to malnutrition inequalities in Vietnam. J. Econ. 2003, 112, 207-223. [CrossRef]

27. Cheng, Y.; Shu, L.-I.; Xiong, X.; Chen, G. The Association of the Digital Divide and Self-rated Health among the Elderly-Taking Beijing as an Example. Sci. Res. Aging 2018, 6, 14-25.

28. Qi, W.; Zhang, W. Class Ladder Consumption in Society Transition. Chongqing Soc. Sci. 2015, $250,641$.

29. Liu, M. Who is going to watch the sports match-Stratum analysis of on-the-spot ornamental sports consumption in the process of urbanization. Sports Sci. 2019, 40, 84-96.

30. He, X. On consumption stratification. Zhejiang J. 2007, 167, 72-76.

31. Li, P.; Zhang, Y. Consumption Stratification: An Important Perspective for Stimulating Economic Development. Soc. Sci. China 2000, 1, 52-61.

32. Drulhe, M. Health and Social: Shaping of Social Health Problems; Yilin Publishing House: Nanjing, China; Press Universitaires de France: Paris, France, 2009; pp. 222-223.

33. Li, X.; Zhou, Z. The Structural Differences of the Social Development and Cultural Changes in Some Less Population Ethnic Groups in Yunnan Province. J. Minzu Univ. China Philos. Soc. Sci. Ed. 2010, 37, 17-24.

34. Zhang, B. Structural contradictions and solutions of people's livelihood problems in China. Ling Dao Zhi You 2013, 1, 52-54. 